\title{
Future changes in extreme precipitation in the Rhine basin based on global and regional climate model simulations
}

\author{
S. C. van Pelt ${ }^{1}$, J. J. Beersma ${ }^{2}$, T. A. Buishand ${ }^{2}$, B. J. J. M. van den Hurk ${ }^{2}$, and P. Kabat ${ }^{1,3}$ \\ ${ }^{1}$ Earth System Science - Climate Change and Adaptive Land and Water Management, Wageningen UR, \\ Droevendaalsesteeg 3, 6708 PB Wageningen, The Netherlands \\ ${ }^{2}$ Royal Netherlands Meteorological Institute (KNMI), P.O. Box 201, 3730 AE De Bilt, The Netherlands \\ ${ }^{3}$ International Institute for Applied System Analysis (IIASA), Schlossplatz 1, 2361 Laxenburg, Austria
}

Correspondence to: S. C. van Pelt (saskia.vanpelt@wur.nl)

Received: 3 May 2012 - Published in Hydrol. Earth Syst. Sci. Discuss.: 25 May 2012

Revised: 13 November 2012 - Accepted: 13 November 2012 - Published: 3 December 2012

\begin{abstract}
Probability estimates of the future change of extreme precipitation events are usually based on a limited number of available global climate model (GCM) or regional climate model (RCM) simulations. Since floods are related to heavy precipitation events, this restricts the assessment of flood risks. In this study a relatively simple method has been developed to get a better description of the range of changes in extreme precipitation events. Five bias-corrected RCM simulations of the 1961-2100 climate for a single greenhouse gas emission scenario (A1B SRES) were available for the Rhine basin. To increase the size of this five-member RCM ensemble, 13 additional GCM simulations were analysed. The climate responses of the GCMs are used to modify an observed (1961-1995) precipitation time series with an advanced delta change approach. Changes in the temporal means and variability are taken into account. It is found that the range of future change of extreme precipitation across the five-member RCM ensemble is similar to results from the 13-member GCM ensemble. For the RCM ensemble, the time series modification procedure also results in a similar climate response compared to the signal deduced from the direct model simulations. The changes from the individual RCM simulations, however, systematically differ from those of the driving GCMs, especially for long return periods.
\end{abstract}

\section{Introduction}

Heavy precipitation events are of importance since they are a major cause of floods, which can have large impacts on society. Based on a wide range of observational and global climate model (GCM) and regional climate model (RCM) studies, changes in greenhouse gas concentrations are expected to affect the frequency and magnitude of extreme precipitation. These studies show an intensification of precipitation extremes over most of Europe (Beniston et al., 2007; Buonomo et al., 2007; Fowler and Ekström, 2009; Frei et al., 2006; Hanel and Buishand, 2011; Kyselý and Beranová, 2009; Kyselý et al., 2011; Nikulin et al., 2011). The projections of changes in the precipitation extremes are sensitive to the choice of RCMs, the driving GCM and the emission scenario. Credible high-resolution climate scenarios for impact studies require an ensemble of RCM simulations driven by multiple GCMs (Fowler et al., 2007; Bernstein et al., 2007). Ideally such ensembles should represent the full range of natural variability and model uncertainty. In practice, however, they are assembled on an opportunity basis, and often the size of the ensembles is restricted by limited resources (Kendon et al., 2010).

For this study the bias-corrected output of five RCM simulations was made available through the RheinBlick2050 project (Görgen et al., 2010), where a comprehensive ensemble of hydrological simulations driven by the output of RCMs was used to analyse future changes in the Rhine discharge regime. The five RCMs were driven by GCMs that were all forced with the A1B SRES emission scenario. It 
is of interest to assess to what degree the results based on such a small sample size describe the uncertainty associated with the model error and natural variability. RCMs can resolve small-scale features, but can still contain large biases, partly inherited from the driving GCMs. The five-member RCM ensemble from the RheinBlick2050 project was extended with an ensemble of $13 \mathrm{GCM}$ simulations to get a better description of the uncertainty induced by the GCM ensemble. Several studies have indicated that this uncertainty exceeds the uncertainty arising from the choice of downscaling techniques and emission scenarios (Graham et al., 2007; Menzel et al., 2006; Prudhomme and Davies, 2009; Rowell, 2006; Wilby and Harris, 2006). Also the GCM ensemble was driven by the A1B emission scenario. Since high-resolution RCM simulations from all these 13 GCM simulations were not available, we followed a pragmatic approach by postprocessing the GCM outputs, using "change factors" (DiazNieto and Wilby, 2005; Arnell and Reynard, 1996), also referred to as the delta change approach (Prudhomme et al., 2002; Te Linde et al., 2010; Lenderink et al., 2007).

Because safety levels along the Rhine are high, this study focused on changes in very rare extreme events. For flood protection in the Netherlands, a design discharge is used that is exceeded, on average, only once in $1250 \mathrm{yr}$. To determine this design discharge, the distribution of the relatively short observed discharge series needs to be statistically extrapolated to the required exceedance probability. Extrapolation of the distributions fitted to the observed flood peaks leads to large uncertainties (Klemeš, 2000a,b). Alternatively, a weather generator has been used (Buishand and Brandsma, 2001) to create long climate time series by resampling the historical data. To be able to analyse extreme discharge, the weather generator can be coupled to a rainfall-runoff model for the Rhine, but this step was not considered in the present study.

This study explores the possibility to combine the future changes in extreme precipitation from an RCM ensemble with the future changes in a GCM ensemble. A new delta change method for precipitation is introduced that allows changes in the extremes to be different from changes in the mean. The range of future changes in extreme multi-day precipitation of the RCM ensemble is compared with the range of the GCM ensemble. A comparison is also made between the signal of the individual RCM simulations and the signal of the driving GCMs. Furthermore, the delta change approach is validated against the use of bias-corrected RCM output.

\section{Study area and data}

\subsection{The Rhine basin}

The river Rhine originates in the Swiss Alps as a mountain river, fed by glacier water, snowmelt and rainfall. From
Switzerland it flows through Germany and the Netherlands into the North Sea. The Rhine basin has an area of about $185000 \mathrm{~km}^{2}$, and the river has a length of $1238.8 \mathrm{~km}$, making it the longest river in Western Europe. The annual mean discharge (1901-2000) at Lobith, where the Rhine enters the Netherlands, is $2200 \mathrm{~m}^{3} \mathrm{~s}^{-1}$. The estimated 1250 -yr return level (the discharge that is exceeded, on average, once in $1250 \mathrm{yr}$ ) at this site is $16000 \mathrm{~m}^{3} \mathrm{~s}^{-1}$.

The climate of the Rhine basin is determined by its location in a Western European zone of temperate climatic conditions with frequent synoptic weather changes. From the northwest to the east and southeast, the maritime climate gradually changes into a more continental climate. Precipitation occurs all year round; mean annual precipitation ranges from about $500 \mathrm{~mm}$ in parts of the Rhine valley to $3000 \mathrm{~mm}$ in some parts of the Alpine region. Spatially averaged annual precipitation sums between 1901 and 2000 (Belz et al., 2007) point towards a slight increase in different sub-regions against a fairly uniform background decadal-scale variability. The increase of precipitation is more pronounced during the hydrological winter (November-April).

\subsection{RCM and GCM data set}

In Table 1 an overview is given of RCM and GCM simulations of which the precipitation output is considered in this study. In the RheinBlick2050 project (Görgen et al., 2010) the RCM simulations were used as input of the hydrological HBV (Hydrologiska Byråns Vattenbalansavdelning) model (Bergström and Forsman, 1973) for the Rhine basin to study the impact of climate change on the discharge in this river basin. We have selected five out of the six RCM simulations used in the RheinBlick2050 project; the ARPEGE-HIRHAM simulation was left out, because the complex reduced grid structure of the ARPEGE model did not allow a straightforward interpolation to a common grid. With the exception of the REMO_10 simulation, the RCM data were obtained from the archive of the ENSEMBLES project (Van der Linden and Mitchell, 2009). Model-specific bias corrections (Görgen et al., 2010) were derived by comparing the RCM control simulations with a high-resolution observed precipitation data set (see Sect. 2.3).

The additional GCM data were obtained from the Coupled Model Intercomparison Project Phase 3 (CMIP3) archive (Meehl et al., 2007). All GCM simulations used are driven by the A1B emission scenario. The GCM output was interpolated to a common $2^{\circ}$ longitude by $2.5^{\circ}$ latitude grid. The Rhine basin is covered by eight grid cells (see Fig. 1). For all GCMs a control run period of $35 \mathrm{yr}$ (1961-1995) and a scenario run period of $20 \mathrm{yr}$ (2081-2100) were used. The choices for these periods were based on data availability. The main problem of unequal sizes is that it may lead to biases in the estimation of parameters used in the delta method. Therefore, changes were also considered with respect to the 20 -yr control periods 1961-1980 and 1976-1995. The averages of 
Table 1. GCM and RCM simulations used in this study. Note that two different transient simulations with the ECHAM5 model (r1 and $\mathrm{r} 3$, which refer to runs with different initial conditions) were used as RCM boundary conditions; two RCMs are forced by ECHAM5r3.

\begin{tabular}{|c|c|c|c|}
\hline GCM & $\mathrm{RCM}$ & GCM references & RCM references \\
\hline CGCM3.1T63 & & Flato (2005) & \\
\hline CNRM-CM3 & & Salas-Mélia et al. (2005) & \\
\hline CSIRO-Mk3.0 & & Gordon et al. (2002) & \\
\hline ECHAM5r1 & REMO_10 & Roeckner et al. (2003) & Jacob (2001) \\
\hline ECHAM5r3 & $\begin{array}{l}\text { RACMO } \\
\text { REMO }\end{array}$ & & $\begin{array}{l}\text { Lenderink et al. (2003) } \\
\text { Jacob (2001) }\end{array}$ \\
\hline GFDL-CM2.0 & & Delworth et al. (2006) & \\
\hline GFDL-CM2.1 & & & \\
\hline HADCM3Q0 & CLM & Gordon et al. (2000) & Steppeler et al. (2003) \\
\hline HADCM3Q3 & HADRM3Q3 & & Jones (2004) \\
\hline IPSL-CM4 & & Marti et al. (2006) & \\
\hline MIROC3.2 hires & & Hasumi and Emori (2004) & \\
\hline MIUB & & Min et al. (2005) & \\
\hline MRI-CGCM2.3.2 & & Yukimoto et al. (2006) & \\
\hline
\end{tabular}

these changes did not differ much from the changes with respect to the 35-yr control run period (1961-1995).

\subsection{Observations}

Observations of precipitation for the Rhine basin were available from the International Commission for the Hydrology of the Rhine basin (CHR). The so-called CHR-OBS data set (De Wit and Buishand, 2007) contains area-averaged daily precipitation for 134 sub-basins of the Rhine basin that were defined for hydrological simulations with the HBV model. The CHR-OBS data cover the period 1961-1995. A newer and longer precipitation data set has become available recently (Photiadou et al., 2011), but this data set could not be used in this study because the bias corrections of the RCM output in the RheinBlick2050 project were based on the CHR-OBS data set. In a companion study, the HBV model was used to analyse and interpret the results described in this paper in terms of changes of flood risk (Ward et al., 2012).

\section{Methodology}

\subsection{Time series transformation}

An advanced delta method was used to transform the CHR observations into a time series that is representative of future conditions consistent with the GCM climate change signal. The delta method makes use of "change factors" and is therefore also referred to as the delta change approach. The most simple form of the delta method (sometimes referred to as the "classical delta method") only considers changes in the mean. The change in the mean may vary seasonally throughout the year or spatially. When coupling with impact models is required (e.g. with a hydrological model), delta methods have a practical advantage that an observed reference time series at the temporal and spatial scale of interest can be used to represent the current climate. The assumption that one has to make is that changes at the (large) scale of the climate model (GCM) can be directly applied to the (local) scale of the time series.

In this study, a more advanced delta method was used that not only takes changes in the mean into account but also the changes in the extremes. Again these changes can vary seasonally and spatially. Rather than a proportional adjustment of observed precipitation, the following non-linear transformation was applied to the bulk of the data (see also Fig. 1 for a graphical summary of the complete procedure):

$P^{*}=a P^{b}$,

where $P$ and $P^{*}$ represent the observed and future precipitation, respectively, and $a$ and $b$ are the transformation coefficients $(a, b>0)$. Shabalova et al. (2003) showed that this relation between $P^{*}$ and $P$ arises if the parameters of a fitted Weibull distribution are perturbed. Leander and Buishand (2007) used this type of transformation to correct for bias in RCM simulations for the Meuse basin; i.e. Eq. (1) was applied to RCM output rather than observed precipitation as in the present study. In addition, Eq. (1) was modified for large $P$ and the transformation coefficients were smoothed in this study (see below).

Several studies have indicated that extreme discharges in the lower part of the Rhine generally result from extreme multi-day precipitation amounts in the river basin. For instance, during the December 1993 and January 1995 floods precipitation was extreme over a 10-day period (Disse and Engel, 2001; Ulbrich and Fink, 1995). Therefore the future change in (extreme) multi-day precipitation is more relevant than the change in (extreme) daily precipitation. In this study Eq. (1) was applied to non-overlapping 5-day sums (73 5-day periods in a calendar year of 365 days). The 5-day time step 


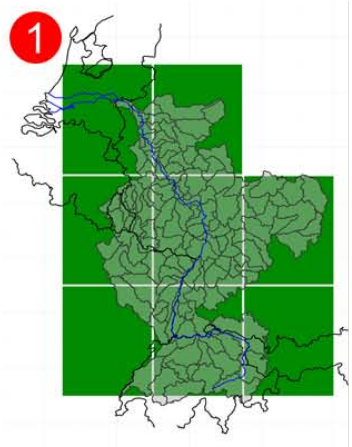

\section{\begin{tabular}{|l|l} 
Rhine basin 8 grid cells and 134 sub basins \\
\hline
\end{tabular}}

Future precipitation $P^{*}$, using signal
from climate model

For $P<P_{90} \quad P^{*}=a P^{b}$

For $P>P_{90} \quad P^{*}=\overline{E^{F}} / \overline{E^{C}} \cdot\left(P-P_{90}^{O}\right)+a\left(P_{90}^{O}\right)^{b}$
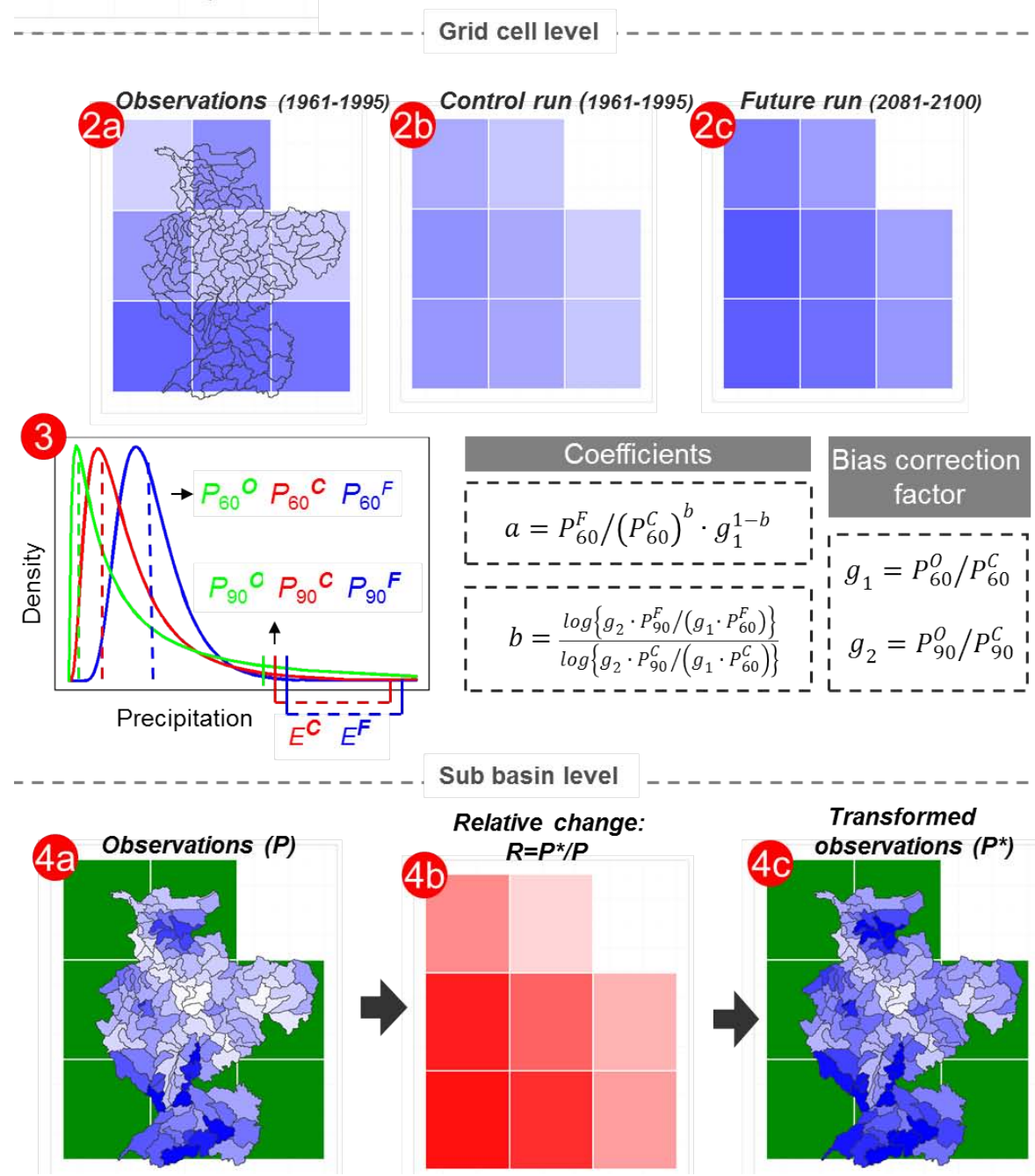

Fig. 1. Overview of the methodology. Panel 1 shows the Rhine basin, divided in 8 (GCM) grid cells and 134 sub-basins. Panel 2 shows the mean precipitation over a 5-day period in each grid cell for the observations and the control and future GCM simulation, all on grid cell level. The observations were upscaled to grid cell level by taking a weighted average over the sub-basins. In panel 3 , the probability density of 5-day precipitation is shown, with the $60 \%\left(P_{60}\right)$ and the $90 \%\left(P_{90}\right)$ quantiles (for the observations as well as for GCM control and future simulations). Also the excess (the amount of precipitation $>$ the $90 \%$ quantile) is shown for the control and the future model run. Panel 4 displays the transformation. The daily observations in each sub-basin were multiplied by the change factor $R$, which was obtained from the observed $(P)$ and transformed $\left(P^{*}\right)$ 5-day precipitation amount and depends on the coefficients $a$ and $b$ and for $P>P_{90}$ also on $\overline{E^{\mathrm{F}}} / \overline{E^{\mathrm{C}}}$. For each sub-basin the daily precipitation was transformed using the GCM signal from the grid cell that contains most of its surface area. 
recognizes the relevance of multi-day precipitation sums, but yet is small enough to be linked with daily precipitation as well.

The coefficients $a$ and $b$ were derived from the $60 \%$ quantile $\left(P_{60}\right)$ and the $90 \%$ quantile $\left(P_{90}\right)$ of the 5-day precipitation sums and the (future) changes therein. Sample quantiles based on the ordered non-overlapping 5-day precipitation amounts were used as estimates of $P_{60}$ and $P_{90} . P_{60}$ was considered because this quantile is generally closer to the mean than the median value $\left(P_{50}\right)$ owing to the positively skewed probability distribution of the 5-day precipitation amounts. $P_{90}$ (which is exceeded on average once in ten 5-day periods) is in the range of the seasonal maximum 5-day precipitation amounts (see Appendix A). Since the transformation given by Eq. (1) represents a monotonic increase, the quantiles of the transformed 5-day precipitation sums are simply obtained by applying the same transformation to the quantiles of the observed 5-day precipitation:

$P_{60}^{*}=a\left(P_{60}\right)^{b}$

$P_{90}^{*}=a\left(P_{90}\right)^{b}$.

From these two equations, first $b$ was solved by eliminating $a$ (Leander and Buishand, 2007):

$b=\frac{\log \left(P_{90}^{*} / P_{60}^{*}\right)}{\log \left(P_{90} / P_{60}\right)}$.

Once $b$ was determined, $a$ was obtained by substituting $b$ into Eq. (2):

$a=P_{60}^{*} /\left(P_{60}\right)^{b}$.

If there is no bias in the $60 \%$ quantile $P_{60}^{\mathrm{C}}$ and the $90 \%$ quantile $P_{90}^{\mathrm{C}}$ in the GCM control simulation compared to the observations, the quantiles $P_{60}^{\mathrm{C}}$ and $P_{90}^{\mathrm{C}}$ can be substituted for $P_{60}$ and $P_{90}$ in Eqs. (4) and (5), and the quantiles $P_{60}^{\mathrm{F}}$ and $P_{90}^{\mathrm{F}}$ in the future climate for $P_{60}^{*}$ and $P_{90}^{*}$. However, if $P_{60}$ and $P_{90}$ are biased, this method results in a transformation that does not reproduce the relative changes in these quantiles. In order to ensure that the relative changes of $P_{60}$ and $P_{90}$ in the transformed series correspond to the relative changes of these quantiles in the GCM simulation, the following biascorrection factors were introduced:

$g_{1}=P_{60}^{\mathrm{O}} / P_{60}^{\mathrm{C}}$

$g_{2}=P_{90}^{\mathrm{O}} / P_{90}^{\mathrm{C}}$,

where the superscript $C$ again refers to the GCM control climate and $O$ refers to observed (reference) data. These corrections were applied to $P_{60}^{\mathrm{C}}$ and $P_{90}^{\mathrm{C}}$ as well as $P_{60}^{\mathrm{F}}$ and $P_{90}^{\mathrm{F}}$. The coefficients $a$ and $b$ then become

$b=\frac{\log \left\{g_{2} \cdot P_{90}^{\mathrm{F}} /\left(g_{1} \cdot P_{60}^{\mathrm{F}}\right)\right\}}{\log \left\{g_{2} \cdot P_{90}^{\mathrm{C}} /\left(g_{1} \cdot P_{60}^{\mathrm{C}}\right)\right\}}$

$a=P_{60}^{\mathrm{F}} /\left(P_{60}^{\mathrm{C}}\right)^{b} \cdot g_{1}^{1-b}$.
Note that the classical delta change method is obtained by assuming that the GCM responses in the 60 and $90 \%$ quantiles are equal:

$P_{90}^{\mathrm{F}} / P_{90}^{\mathrm{C}}=P_{60}^{\mathrm{F}} / P_{60}^{\mathrm{C}}$

leading to $b=1$ and $a=P_{60}^{\mathrm{F}} / P_{60}^{\mathrm{C}}$, and therefore Eq. (1) reduces to $P^{*}=a P$.

\section{Transformation for large $P$}

Equation (1) was applied to the observed values for which $P \leq P_{90}^{\mathrm{O}}$. For larger $P$ this equation is not flexible enough to reproduce the changes in the extremes adequately. This could be improved by separately addressing the change in the excesses, $E=P-P_{90}$, i.e. the events exceeding $P_{90}$. The mean excesses for the control and future period were defined as

$\overline{E^{\mathrm{C}}}=\frac{\sum E^{\mathrm{C}}}{n^{\mathrm{C}}}$ and $\overline{E^{\mathrm{F}}}=\frac{\sum E^{\mathrm{F}}}{n^{\mathrm{F}}}$

where $n^{\mathrm{C}}$ and $n^{\mathrm{F}}$ are the numbers of 5-day periods in which the $90 \%$ quantile is exceeded in the control and future run, respectively. The size of the mean excess is closely related to the slope of an extreme-value plot of the seasonal maximum 5-day precipitation amounts (see Appendix A).

To ensure that the transformation reproduces the change in the mean excess, Eq. (1) was modified as

$P^{*}=\overline{E^{\mathrm{F}}} / \overline{E^{\mathrm{C}}} \cdot\left(P-P_{90}^{\mathrm{O}}\right)+a\left(P_{90}^{\mathrm{O}}\right)^{b}$ for $P>P_{90}^{\mathrm{O}}$.

Effectively the excess scales linearly with the factor $\overline{E^{\mathrm{F}}} / \overline{E^{\mathrm{C}}}$. The use of Eq. (11) also avoids unrealistically high precipitation amounts, which may occasionally occur when Eq. (1) is used for $P>P_{90}^{\mathrm{O}}$ if $b>1$.

In principle the coefficients $a$ and $b$ and the change in the mean excesses $\overline{E^{\mathrm{F}}} / \overline{E^{\mathrm{C}}}$ may vary seasonally and spatially. To reduce sampling variability in the transformation coefficients, we chose to use smoothed but distinct values of $a, b$ and $\overline{E^{\mathrm{F}}} / \overline{E^{\mathrm{C}}}$ for each calendar month. First, the quantiles $P_{60}$ and $P_{90}$ were estimated for each calendar month using six 5-day periods for the calendar months January to November and seven 5-day periods for December. These monthly estimates of $P_{60}$ and $P_{90}$ were subsequently smoothed over time by using a 3 -month moving average with weights $1 / 4,1 / 2$ and $1 / 4$. The mean excesses $\overline{E^{\mathrm{C}}}$ and $\overline{E^{\mathrm{F}}}$ were smoothed over time similarly. The temporally smoothed estimates of $P_{60}$ and $P_{90}$ were used in Eq. (8) to obtain a temporally smoothed value of $b$ for each calendar month and for each grid cell in the basin. To reduce sampling variability further, the median value of $b$ over the eight grid cells for each calendar month was used for all grid cells in the basin. Analogously, the median of $\overline{E^{\mathrm{F}}} / \overline{E^{\mathrm{C}}}$ over the eight grid cells was taken for each calendar month. The coefficient $a$ finally varies spatially (a distinct value for 

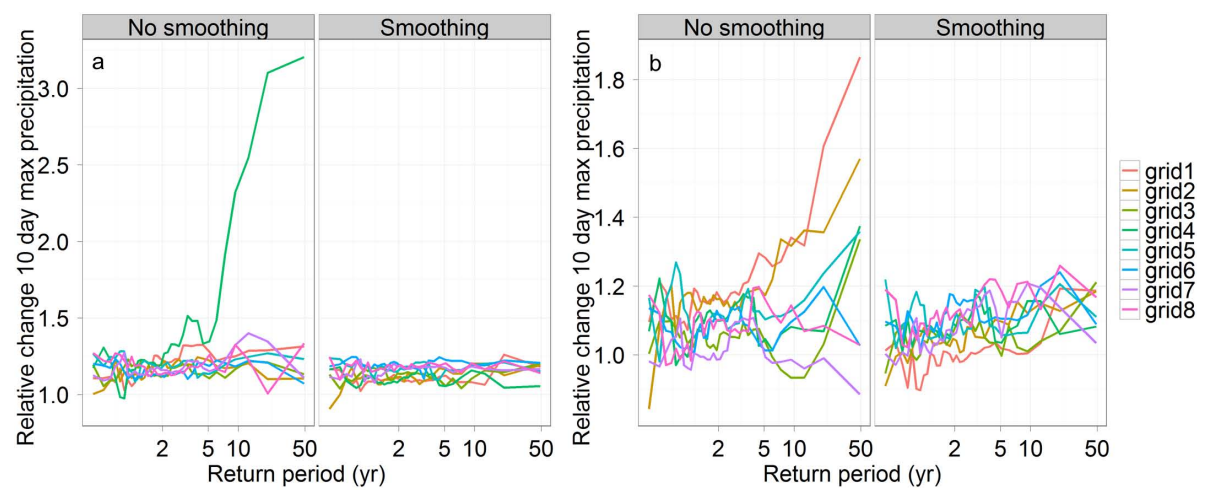

Fig. 2. Relative changes of the return levels of 10-day precipitation in the winter half-year (October-March) for each of the eight GCM grid cells covering the Rhine basin. Panel (a): results for the CGCM3.1T63 simulation; panel (b): results for the ECHAM5r1 simulation. Within both panels, the left part shows the results for no temporal and spatial smoothing and the right part shows the results with smoothing. Note the difference in plotting scale for the CGCM3.1T63 and ECHAM5r1 results.

each grid cell in the basin) and was obtained by using the temporally smoothed $P_{60}$ and the spatially uniform value of $b$ in Eq. (9).

Here daily precipitation amounts for the $134 \mathrm{HBV}$ subbasins in the Rhine basin for the period 1961-1995 were used as the baseline time series. Equations (1) and (11), however, apply to the area-average precipitation over a GCM grid cell. The precipitation amounts for the HBV sub-basins were therefore aggregated to grid cell values by taking an areaweighted average of all sub-basins lying in the respective grid cell. After the transformation using Eqs. (1) and (11), the final step involved the disaggregation of the transformed 5-day precipitation values at the GCM grid cell into daily precipitation at the sub-basin scale. For this a change factor $R$ was defined for each grid cell and 5-day period as

$R=P^{*} / P$.

Each daily observation in a sub-basin allocated to a given GCM grid cell was transformed according to the corresponding value of $R$. Thus, the daily observations in a 5-day period obtained the same relative change. The method ensures that the change in the temporally and spatially aggregated daily precipitation of the sub-basins corresponds to the change in the 5-day precipitation over the grid cell. The non-linear nature of Eqs. (1) and (11) generally results in different change factors for days in distinct 5-day intervals. The result is a future time series of daily precipitation on sub-basin level.

\subsection{Exploring the sensitivity of choices}

In the process of developing and applying the advanced delta change method, a number of choices were made. These choices influence the changes in the return levels of extreme precipitation. In this section, the sensitivity of the results to some of these choices is discussed.

Temporal and spatial smoothing was applied to reduce the influence of sampling noise on the estimated climate change signal. Spatial variation of $b$ and $\overline{E^{\mathrm{F}}} / \overline{E^{\mathrm{C}}}$ was ignored. The need for temporal and spatial smoothing is shown in Fig. 2 for two GCM simulations. The changes from the model output were used to transform the observed data, both with and without temporally and spatially smoothed coefficients in Eqs. (1) and (11). The figure gives the relative changes of the return levels of 10-day precipitation for the winter half-year (October-March) as a function of return period. The winter half-year is the main season of interest for high river discharge in the lower part of the Rhine basin.

The changes are shown for each grid cell of the Rhine basin separately. Similar figures were made for all other GCM simulations. For the transformed data based on the CGCM3.1T63 simulation (panel a of Fig. 2), an unrealistically large increase for return periods $>10 \mathrm{yr}$ was found at grid cell 4 when no smoothing was applied. A physically plausible explanation is lacking for the huge precipitation amounts resulting from the changes of a factor of 3 or more in the right tail of the distribution.

The results for the ECHAM5r1 simulation (panel b) are characteristic for most other GCM simulations. The spread of the relative changes strongly increases with increasing return period when temporal and spatial smoothing were not applied. Smoothing also improved the correspondence between the changes in the mean precipitation and the mean 10-day maximum basin-average precipitation from the transformed time series and the changes in these properties from the climate model output (not shown).

The effect of different choices for temporal smoothing on the relative changes of the 10-yr return level of the 10-day basin-average precipitation in the winter half-year is shown in Fig. 3. The range of these changes is similar for the first three smoothers, but grows when less or no smoothing is applied. It further turned out that the degree of spatial smoothing has little effect on the relative changes in the 10-yr return level of the 10-day basin average precipitation. 


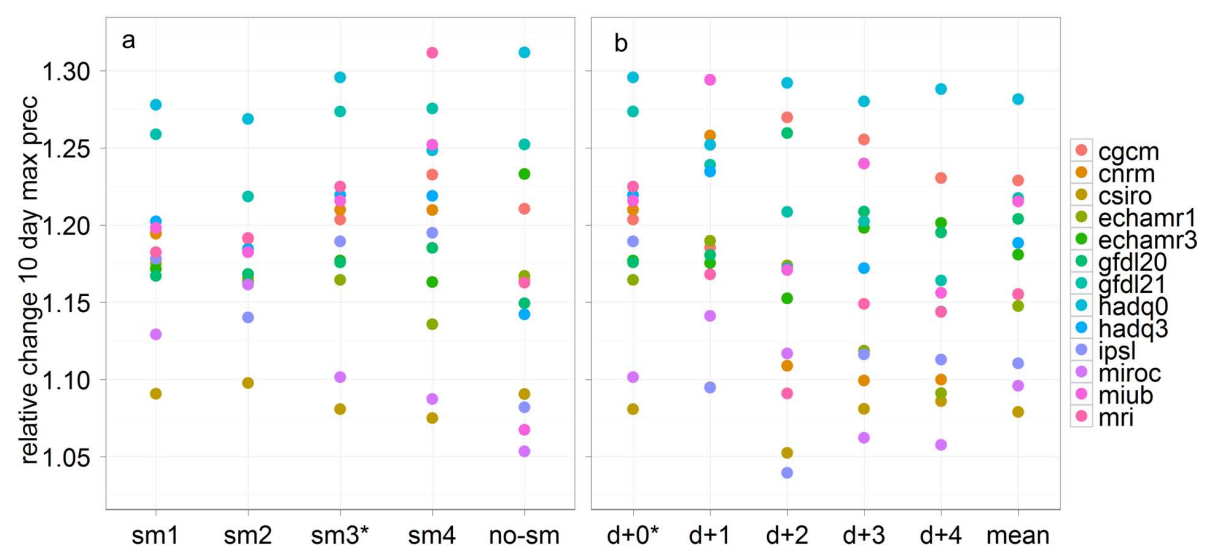

Fig. 3. Relative changes of the 10-yr return level of the 10-day basin-average precipitation in the winter half-year (October-March) for each GCM. Panel (a) shows the effect of different choices for temporal smoothing: two 5-month moving averages with weights 1/16, 1/8, 3/8, 1/8, $1 / 16(\mathrm{sm} 1)$ and 1/8, 1/4, 1/4, 1/4, 1/8 (sm2), two 3-month moving averages with weights 1/4, 1/2, 1/4 (sm3) and 1/8, 3/4, 1/8 (sm4) and no temporal smoothing (no-sm). Panel (b) shows the effect of shifting the 5-day period. Mean indicates the mean of the relative changes of the 5 different shifts for each GCM simulation. The asterisk indicates the type of smoothing (a) or the 5-day period (b) used in this study.

The coefficients and quantiles (described in Sect. 3.1) were based on non-overlapping 5-day precipitation sums. The sensitivity of shifting the 5-day period 1 to 4 days on the relative changes of the 10-yr return level of 10-day basin-average precipitation is also shown in Fig. 3. A shift of the 5-day period has a marked effect for some climate model simulations; the overall effect on the ensemble range is small.

The sensitivity to the bias correction of the 60 and $90 \%$ quantiles of the 5-day precipitation sums in the GCM simulations was tested by comparing the relative changes in the mean 10-day maximum basin-average precipitation in the raw GCM model output to the changes in the transformed data taking either $g_{1}$ and $g_{2}$ as specified using Eqs. (6) and (7) or $g_{1}=g_{2}=1$, i.e without bias correction. Figure 4 shows the results for the summer half-year (April-September) and the winter half-year (October-March). For summer the bias correction on both $P_{60}$ and $P_{90}$ leads to the best correspondence between the transformed time series and the direct GCM simulations. For winter the bias corrections only play a minor role.

\subsection{Resampling}

To estimate quantiles of the distributions of extreme precipitation amounts, a 3000-yr synthetic sequence of daily precipitation was available for each HBV sub-basin from the work of Beersma (2002). Daily precipitation was generated with daily temperature using nearest neighbour resampling from the 35-yr record of historical observations. The 3000-yr precipitation series were transformed to future time series with the advanced delta method described in Sect. 3.1.

The method of time-series resampling of meteorological variables in the Rhine basin applied in this study was originally developed as part of a new methodology to determine the design discharge for flood protection in the Netherlands

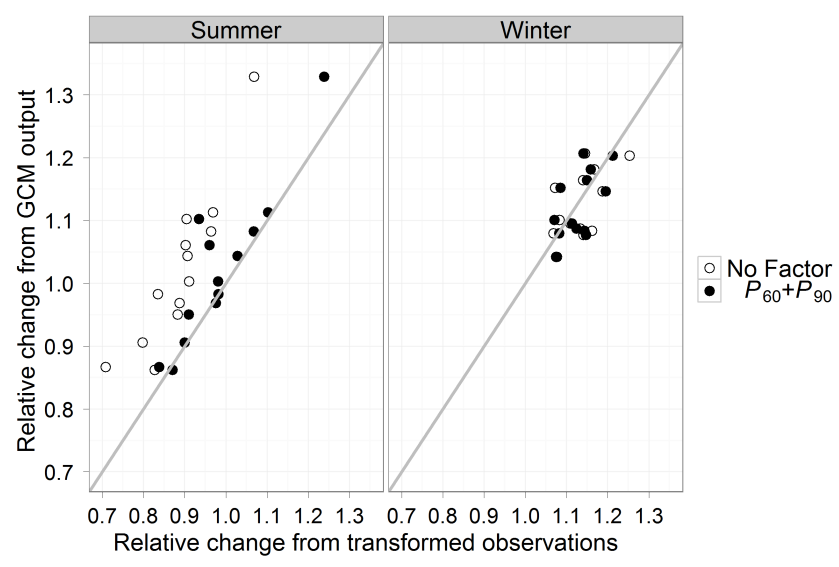

Fig. 4. Comparison of the relative change (future versus present day) of the mean 10-day maximum basin-average precipitation derived directly from the raw GCM model output versus the change obtained from the transformation procedure for summer (left panel) and winter (right panel). Relative changes from the transformed observations are shown for no bias correction (No Factor) and for bias correction on $P_{60}$ and $P_{90}\left(P_{60}+P_{90}\right)$. The grey line represents optimal correspondence (i.e. the $1: 1$ line).

(Beersma and Buishand, 2003; Wójcik et al., 2000). Leander and Buishand (2007) and Leander et al. (2008) applied the same methodology for the first time to RCM data, but for the Meuse basin. Recently it has also been applied for the Rhine basin using time series from the RACMO RCM driven by the ECHAM5 GCM (Te Linde et al., 2010) and from an ensemble of RCMs in the RheinBlick2050 project (Görgen et al., 2010). The resampled RCM data from the RheinBlick2050 project were made available for the present study.

Nearest-neighbour resampling was used to reproduce temporal correlation and to preserve the dependence between 
daily precipitation and temperature (Rajagopalan and Lall, 1999). In the multi-site application for the Rhine basin, daily precipitation and temperature were sampled simultaneously with replacement from the historical data to preserve their mutual dependencies. Summary statistics of the daily precipitation and temperature fields were needed in this application to avoid problems with the high-dimensional data space (Buishand and Brandsma, 2001). In each simulation step, the 10 nearest neighbours of the last generated day in terms of these summary statistics are searched for in the historical data. Details about the sensitivity of the autocorrelation and the simulated extremes to the summary statistics used and parameters in the resampling procedure can be found in Buishand and Brandsma (2001).

To reduce the effect of seasonal variation, the search for nearest neighbours was restricted to days within a moving window of 61 days, centred on the calendar day of interest (Beersma, 2002; Wójcik et al., 2000). Daily precipitation was standardized by dividing by the mean wet-day precipitation amount of the calendar day of interest.

\section{Results}

\subsection{Change in mean, standard deviation and quantiles}

Table 2 presents the changes in the 60 and $90 \%$ quantiles and the change in the mean excess after the transformation defined by Eqs. (1) and (11) has been applied to the 5-day sums of the observed precipitation series for all model simulations presented in Table 1. From Table 2 it can be seen that for the GCM simulations the changes in the $90 \%$ quantile and especially the mean excess $(\bar{E})$ are generally stronger than the changes in the $60 \%$ quantile, which supports the use of a non-linear delta method. In particular for GFDL2.1CM2.1 and IPSL-CM4 the change in the mean excess largely exceeds the change in the 60 and $90 \%$ quantiles. In contrast, the relative changes in $P_{60}, P_{90}$ and mean excess are very similar for the RCM simulations. Also, the relative changes for the RCM output processed with the delta method are similar to those for the bias-corrected RCM output from the RheinBlick2050 project. However, the relative changes for the RCMs generally differ from the relative changes of their driving GCM. The RCMs exhibit a smaller change in the mean excess $(\bar{E})$ than their driving GCM, except those forced by ECHAM5r3.

For the remaining part of this paper, the results for the RCMs will refer to those obtained by the delta method, except when stated differently. In Table 3 changes in the mean precipitation and the standard deviation of the 5-day precipitation sums are shown. The mean precipitation increases in winter and decreases in summer. For the GCM simulations the increase in the standard deviation of the 5-day precipitation sums is larger than the increase in the mean. This is consistent with the relatively large changes in the upper tail
Table 2. Relative changes in the $60 \%$ quantile $\left(P_{60}\right)$, the $90 \%$ quantile $\left(P_{90}\right)$ and mean excess $(\bar{E})$ after a transformation of the 5-day precipitation sums of the observed precipitation based on the simulated changes between 1961-1995 and 2081-2100 of a GCM or RCM. The changes are basin-average relative changes for the winter half-year (October-March). The changes between the observed and transformed data were obtained by taking the median of the relative changes of the temporally smoothed estimates for each calendar month over the eight grid cells at the common GCM resolution and averaging these medians for the winter half-year. For the RCMs, the transformation was applied after the RCM output was aggregated to the GCM grid resolution. The results in the columns headed $P_{60}^{\mathrm{DIR}}, P_{90}^{\mathrm{DIR}}$ and $\bar{E}^{\mathrm{DIR}}$ refer to the direct use of bias-corrected RCM output from the RheinBlick2050 project. For the latter, the relative changes were based on the differences between the RCM control and RCM future period.

\begin{tabular}{lcccccc}
\hline GCM/RCM & $P_{60}$ & $P_{90}$ & $\bar{E}$ & $P_{60}^{\text {DIR }}$ & $P_{90}^{\text {DIR }}$ & $\bar{E}^{\text {DIR }}$ \\
\hline CGCM3.1T63 & 1.10 & 1.11 & 1.22 & & & \\
CNRM-CM3 & 0.97 & 1.04 & 1.28 & & & \\
CSIRO-Mk3.0 & 1.01 & 1.05 & 1.17 & & & \\
ECHAM5r1 & 0.98 & 1.04 & 1.25 & 1.12 & 1.08 & 1.07 \\
ECHAM5r1-REMO_10 & 1.11 & 1.10 & 1.00 & & & \\
ECHAM5r3 & 1.11 & 1.15 & 1.11 & 1.21 & 1.22 & 1.19 \\
ECHAM5r3-RACMO & 1.18 & 1.19 & 1.21 & 1.19 & 1.16 & 1.14 \\
ECHAM5r3-REMO & 1.16 & 1.14 & 1.15 & & & \\
GFDL-CM2.0 & 1.04 & 1.11 & 1.21 & & & \\
GFDL-CM2.1 & 1.05 & 1.10 & 1.41 & & & \\
HADCM3Q0 & 1.12 & 1.17 & 1.35 & 1.02 & 1.12 & 1.04 \\
HADCM3Q0-CLM & 1.03 & 1.10 & 1.07 & & & \\
HADCM3Q3 & 1.07 & 1.12 & 1.20 & 1.17 & 1.13 & 1.21 \\
HADCM3Q3-HADRM3 & 1.18 & 1.10 & 1.17 & & & \\
IPSL-CM4 & 0.89 & 1.01 & 1.36 & & & \\
MIROC3.2 & 0.94 & 1.03 & 1.19 & & & \\
MIUB & 0.95 & 1.09 & 1.24 & & & \\
MRI-CGCM2.3.2 & 1.05 & 1.09 & 1.34 & & & \\
MEAN GCMs & 1.02 & 1.08 & 1.26 & & & \\
MEAN RCMs & 1.13 & 1.13 & 1.12 & 1.14 & 1.14 & 1.13 \\
\hline
\end{tabular}

Table 3. Relative changes in mean precipitation and the standard deviation $(\sigma)$ of the 5-day precipitation sums after the transformation of the observations according to the changes in the GCM and RCM simulations. The changes are shown for the winter half-year (October-March) and the summer half-year (April-September).

\begin{tabular}{lcclccc}
\hline & \multicolumn{2}{c}{ Winter } & & \multicolumn{2}{c}{ Summer } \\
\cline { 2 - 3 } \cline { 5 - 6 } & Mean & $\sigma$ & & Mean & $\sigma$ \\
\hline Mean GCMs & 1.08 & 1.15 & & 0.88 & 1.02 \\
Mean RCMs & 1.13 & 1.12 & & 0.91 & 1.06 \\
\hline
\end{tabular}

of the distribution $\left(P_{90}, \bar{E}\right)$ in these simulations. For both the GCM and RCM simulations, the decrease in mean summer precipitation is accompanied by an increase in the standard deviation of the 5-day precipitation sums. 

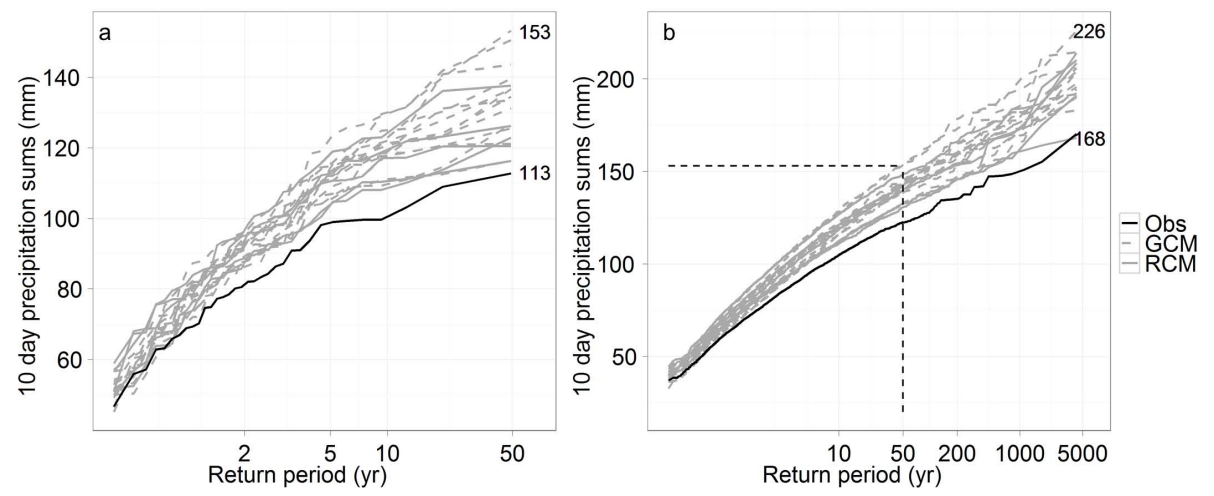

Fig. 5. Gumbel plots of the maximum 10-day basin-average precipitation in winter (October-March) for the future climate (end of the 21 st century) from the short time series of transformed observations - $35 \mathrm{yr}$, panel (a) - and those from the long time series of transformed resampled observations $-3000 \mathrm{yr}$, panel (b). The black line represents the maximum 10-day basin average precipitation sums in the (resampled) observations; the dashed grey lines refer to transformed observations based on the 13 GCM simulations and the solid grey lines refer to the 5 RCM simulations. The horizontal and vertical dashed black lines in the right panel mark the extension of the left panel.

\subsection{Precipitation extremes in short and long time series from the GCM-RCM ensemble}

To assess the possible future change in the occurrence of extreme precipitation, the maximum 10-day basin-average precipitation amounts in the winter half-year from the transformed time series for future climate conditions were compared with those in the observed time series for the original 35-yr series as well as the resampled 3000-yr series (Fig. 5). The spread between the future 10-day precipitation amounts is small at short return periods, but becomes larger at long return periods. For return periods between 10 and $50 \mathrm{yr}$, the spread for the resampled 3000-yr series is about $25 \%$ smaller than the spread for the original 35-yr series. For the 3000yr series, the total ensemble spans a range from almost no change compared to the observations to an increase of about $30 \%$ at the longest return periods.

\subsection{Range of return levels of maximum 10-day precipitation sums in the GCM and RCM ensemble}

In Fig. 6 four return levels of the 10-day winter maximum basin-average precipitation for 2081-2100 are shown. These return levels are based on the 3000-yr resampled time series. The return levels were derived empirically from the ordered sample of the 10-day maxima. For the 1000-yr return level, a distribution was fitted to the 15 largest values using an approach due to Weissman (1978) because of the small number of exceedances of this return level (see also Appendix B). The return levels from the 3000-yr resampled observations are inserted in Fig. 6 as the references representing current climate conditions. For the bias-corrected RCM output from the RheinBlick2050 project, each return level for the future climate was obtained by multiplying the relative difference in that return level between the future and control simulation with the reference value.

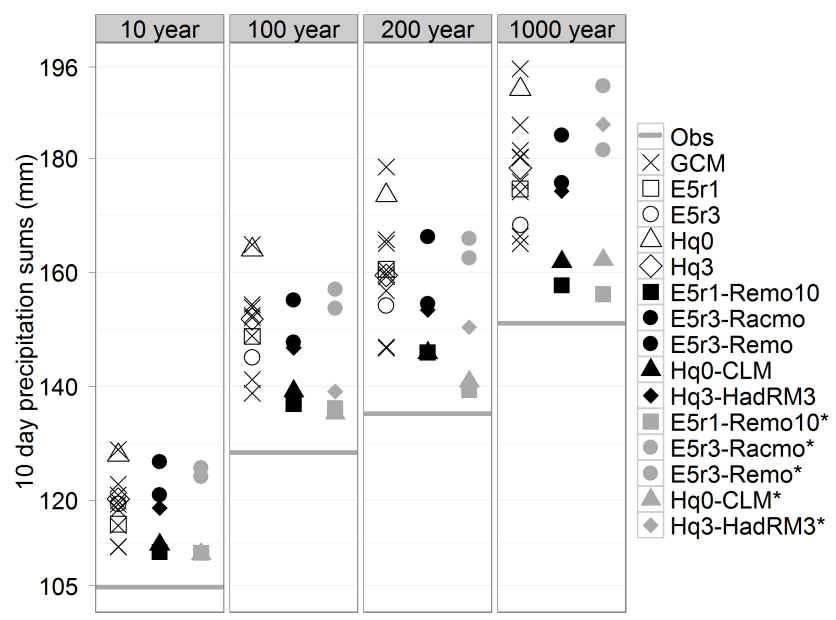

Fig. 6. Ranges of return levels of 10-day basin-average precipitation for four return periods for the future climate (end of 21 st century). The results are shown for the transformed observations based on the RCM and GCM ensembles and for the bias-corrected RCM output from the RheinBlick2050 project. All GCM results are plotted in the first column of symbols. Open symbols represent GCM simulations that force at least one RCM; crosses refer to the results from the other GCM simulations. The second column represents transformed observations based on RCM simulations while the third column refers to the bias-corrected RCM output. The RCMs are indicated by the same symbol as used for the driving GCM (in the first column). The grey horizontal lines denote the return levels of the 10-day basin-average precipitation from the reference observations (i.e. the current climate).

For the 10-yr return level, the mean and spread in the GCM ensemble are comparable to those in the (delta method) RCM ensemble. For the 100-, 200- and 1000-yr return levels, the mean for the future period in the GCM ensemble is larger than the mean in the RCM ensemble. The spread within the 
GCM ensemble is slightly larger than the spread within the RCM ensemble for these return levels. This may be attributed to the larger size of the GCM ensemble (13 compared to five for the RCM ensemble). While the two RCM simulations that are forced by ECHAM5r3 show larger return levels of 10-day maximum basin-average precipitation than the driving GCM, all other RCM simulations show lower return levels than the forcing GCM, in agreement with the changes in $\bar{E}$ presented in Table 2. In particular for CLM the difference with the signal from the driving GCM is large for all return periods. For the RCM simulations, the changes in the return levels obtained from the bias-corrected model output are comparable to those generated with the delta method.

\section{Discussion and conclusions}

This study explored the options to expand an existing range of RCM projections of changes in extreme multi-day precipitation in the Rhine basin, using an ensemble of GCM projections. The results of this study allow for a number of conclusions.

First, the selection of RCMs used in the RheinBlick2050 project does not appear to be strongly biased with respect to the multi-day extreme precipitation change imposed by the small ensemble of driving GCMs. As shown in Fig. 6, the small number of driving GCMs for the RCM simulations from the RheinBlick2050 project covers the ranges deduced from the ensemble of $13 \mathrm{GCM}$ simulations fairly well; the driving GCMs do not form a cluster or contain major outliers. When we look at the total ensemble, we see that the ranges covered by the RCM simulations and the GCM simulations are similar. The ARPEGE-HIRHAM5 simulation, which was excluded in the present study, does not alter this result because of its intermediate changes with respect to the other RCM simulations from the RheinBlick2050 project (see 6364 pp. of the RheinBlick2050 report; Görgen et al., 2010).

Second, for the RCM simulations the advanced non-linear delta method applied in this study generates a range of extreme multi-day precipitation changes that is similar to the range obtained directly from the bias-corrected RCM simulations from the RheinBlick2050 project. This gives confidence in the application of the advanced non-linear delta method, using an ensemble of model projections. Responses derived from individual RCMs did show modest sensitivity to the selected method, but their ranking is similar for the two methods, which confirms our confidence in the advanced delta method.

Third, the multi-day extreme precipitation signal deduced from the RCMs is not trivially related to the response derived from the driving GCMs. For three out of five RCM-GCM combinations, the RCM output leads to a smaller change of extreme 10-day precipitation sums than the corresponding GCM output. The two RCMs forced by ECHAM5r3 showed an increase in the change of the extreme 10-day precipitation sums, compared to the GCM output. Especially at long return periods, the individual paired GCM and RCM simulations show systematic differences. This could indicate that the RCMs have an influence on the signal of their driving GCMs, but the small number of simulations explored here permits neither a firm conclusion on the origin, nor robustness of this difference. Further research with larger ensembles and systematic exploration of potential causes is needed. Possible causes of this response are locally generated natural variability (to be tested with larger ensembles), different physical expressions or parameterizations at higher spatial resolution, or dynamical/physical feedbacks that are represented differently by the driving GCM and the nested RCM.

The advanced delta method applied in this study is useful as it is relatively cheap and there is no bias in the reference time series. However, it has also some limitations. Since it is not physically but statistically based, it potentially ignores relevant processes or feedbacks. The delta method as applied here neglects changes in the shape of the right tail of the distribution, by using a linear scaling of the excess above $P_{90}$. It is, however, not possible to obtain reliable estimates of changes in the shape of the upper tail of the distribution from relatively short climate model simulations. This leads to a large uncertainty about the change in extremes, which is not taken into account in the present study. In addition the delta method required some subjective choices regarding temporal and spatial smoothing to control noise due to sampling uncertainty. In particular, the degree of temporal smoothing has some influence on the range of the relative changes of the 10yr return level of 10-day basin-average precipitation. As for other methods, the results of the delta method are influenced by sampling uncertainty resulting from the limited length of the observed and climate model time series, especially for long return periods.

For developing climate adaptation measures that deal with (future) flood risk, it is important to have knowledge about the changes in precipitation extremes. The results of this study provide an opportunity to base adaptation measures on an ensemble of 18 climate model simulations, which for current standards can be considered a large ensemble. The range of future changes in extreme multi-day precipitation, based on an ensemble of both GCMs and RCMs, gives more insight into the possible upper and lower bound of such changes, which is important information for water managers and flood risk studies (Ward et al., 2012). Figure 6 shows that using a sub-sample of GCM or RCM results alone could lead to an underestimation of the uncertainty range of future return levels, in particular for long return periods. Ideally, multi-model ensembles should therefore contain both RCM and GCM based results. However, as long as the RCMs and GCMs show different responses and the nature of these differences is unexplained, the authors recommend to present the responses for the different model ensembles separately. This allows the user of this information to become aware that 
differences in the responses are (at least in part) related to differences in the type of climate model used.

\section{Appendix A}

\section{Relation between parameters in the transformation formula and extreme-value characteristics}

In this appendix we relate the $90 \%$ quantile $P_{90}$ and the mean excess to properties of the distribution of seasonal maximum precipitation amounts. In the hydrological literature the generalized Pareto (GP) distribution has often been used to describe the distribution of the excesses of a high threshold $u_{0}$ (e.g. Beguería, 2005; Van Montfort and Witter, 1986):

$\operatorname{Pr}\left(P-u_{0} \leq x \mid P>u_{0}\right)= \begin{cases}1-\left(1+\frac{\kappa x}{\alpha_{0}}\right)^{-1 / \kappa}, & \kappa \neq 0 \\ 1-\exp \left(-\frac{x}{\alpha_{0}}\right), & \kappa=0\end{cases}$

where $\alpha_{0}$ is the scale parameter and $\kappa$ the shape parameter. For $\kappa=0$ the GP distribution reduces to the exponential distribution. In our application $P$ is the precipitation sum in an arbitrary 5-day interval. A reasonable assumption is that the consecutive 5-day values are independent. The number $K_{0}$ of exceedances of $u_{0}$ in a given season follows then a Poisson distribution with parameter $\lambda_{0}$ (the mean number of exceedances) if $u_{0}$ is sufficiently high. For the distribution of the seasonal maximum $P_{\max }$,

$H(x)=\operatorname{Pr}\left(P_{\max } \leq x\right)=\left\{\begin{array}{lr}\exp \left\{-\left[1+\xi\left(\frac{x-\mu}{\sigma}\right)\right]^{-1 / \xi}\right\}, & \xi \neq 0 \\ \exp \left\{-\exp \left[-\left(\frac{x-\mu}{\sigma}\right)\right]\right\}, & \xi=0\end{array}\right.$

which is a generalized extreme value (GEV) distribution with location parameter $\mu$, scale parameter $\sigma$, and shape parameter $\xi$. The case $\xi=0$ is known as the Gumbel distribution. The three GEV distribution parameters are uniquely determined by the Poisson parameter $\lambda_{0}$ and the GP distribution parameters $\alpha_{0}$ and $\kappa$ (Buishand, 1989; Wang, 1991):

$\mu=\left(\begin{array}{l}u_{0}-\frac{\alpha_{0}}{\kappa}\left(1-\lambda_{0}^{\kappa}\right), \kappa \neq 0 \\ u_{0}+\alpha_{0} \ln \left(\lambda_{0}\right), \quad \kappa=0\end{array}\right.$

$\sigma=\alpha_{0} \lambda_{0}^{\kappa}$

$\xi=\kappa$.

Note that Eq. (A2) only represents the distribution of the seasonal maxima for $P_{\max } \geq u_{0}$.

An important property of the GP distribution is that, for all thresholds $u>u_{0}$, the excesses follow also a GP distribution with the same shape parameter $\kappa$ but with a different scale parameter $\alpha$ (e.g. Wang, 1991; Coles, 2001). The latter is related to the GEV scale parameter $\sigma$ in the same way as $\alpha_{0}$ :

$\sigma=\alpha \lambda^{\kappa}$, where $\lambda$ is the mean number of exceedances of $u$ in the season of interest. The mean of the excesses is given by (Coles, 2001)

$\mu_{\mathrm{E}}=\frac{\alpha}{1-\kappa}, \quad \kappa<1$.

The GEV scale parameter gives the slope of the extremevalue plot of the seasonal maxima. From Eqs. (A4) and (A5), it follows

$\sigma=\lambda^{\kappa}(1-\kappa) \mu_{\mathrm{E}}, \quad \kappa<1$.

Hence, the GEV scale parameter is proportional to the mean excess. The constant of proportionality depends on the shape parameter. For $\kappa=0$, we have $\sigma=\mu_{\mathrm{E}}$. Because $\kappa$ generally does not differ much from zero for 5-day precipitation maxima, the constant of proportionality is close to 1 .

If the excesses of the observed 5-day precipitation amounts follow a GP distribution, then the transformation (Eq. 11) changes the scale parameter by a factor $\overline{E^{\mathrm{F}}} / \overline{E^{\mathrm{C}}}$ and leaves the shape parameter unchanged. The slope of the extreme-value plot changes by the same factor. The transformation does, however, not make explicitly use of an underlying GP distribution. For instance, in the case of a Weibull distribution, it also changes the scale parameter by a factor $\overline{E^{\mathrm{F}}} / \overline{E^{\mathrm{C}}}$ and leaves the shape parameter unchanged. A different transformation is needed to change the shape of the upper tail of the distribution of $P$. It is, however, difficult to find significant changes in the GP shape parameter.

Assuming independence of the 5-day precipitation sums, the number of exceedances of the $90 \%$ quantile $P_{90}$ in a season of $5 m$ days follows a binomial distribution with parameters $m$ and $p=0.10$. The probability that this quantile is not exceeded in a 90 -day season is then $0.9^{18}=0.150$. For a 180 day season this probability equals $0.9^{36}=0.023$, and thus $P_{90}$ is in the extreme left tail of the distribution of $P_{\max }$. The delta method was also tested using the $95 \%$ quantile $P_{95}$ instead of $P_{90}$. The changes in the mean excesses of $P_{95}$ turned out to be very sensitive to the method used to estimate $P_{95}$ from the ordered sample of non-overlapping 5-day precipitation amounts owing to the small number of exceedances of this quantile in the short time-series used in this study. This sensitivity can be mitigated by taking all possible, overlapping 5-day precipitation amounts into account for estimating $P_{95}$.

\section{Appendix B}

\section{Weissman approach for extreme values}

The 1000-yr return levels and their changes were estimated from the 15 largest values using the Weissman (1978) approach. Let $X_{1 n} \geq X_{2 n} \geq \ldots \geq X_{k n}$ be the $k$ largest values in a sample of size $n$ from a distribution $F$. In this study $F$ refers to the distribution of the 10-day maximum basin - average precipitation in the winter half-year. 
Under certain conditions on $F$, the joint density of $X_{1 n}$, $X_{2 n} \ldots X_{k n}$ can for large $n$ be approximated as (Weissman, 1978)

$f_{1, \ldots, k}\left(x_{1}, \ldots, x_{k}\right)=\sigma^{-k} \exp \left[-e^{-\left(x_{k}-\mu\right) / \sigma}-\sum_{i=1}^{k}\left(x_{i}-\mu\right) / \sigma\right]$

where $\mu$ is a location parameter (which depends on $n$ ) and $\sigma$ is a scale parameter. Equation (B1) applies if, after appropriate scaling, the distribution of the maximum $X_{1 n}$ tends to the Gumbel distribution as $n \rightarrow \infty$.

Maximization of the density $f_{1, \ldots, k}$ with respect to $\mu$ and $\sigma$ yields the maximum likelihood estimates:

$\hat{\sigma}=\bar{X}_{k n}-X_{k n}$

$\hat{\mu}=X_{k n}+\hat{\sigma} \ln k$

where $\bar{X}_{k n}$ is the average of the $k$ largest values. The $T$-year return level $x_{T}$ is then estimated as

$\hat{x}_{T}=X_{k n}+\hat{\sigma} \ln (k T / n)$.

In this study $T=1000, n=3000$ and $k=15$. Taking $k=100$ instead of $k=15$ had almost no influence on the bandwidth of the estimated 1000-yr return levels.

Acknowledgements. This research was carried out in the framework of the Dutch National Research Programme "Climate changes Spatial Planning", as part of the project "Attention for Safety 2" and in the framework of the Dutch National Research Programme "Knowledge for Climate". We thank Philip Ward, Jeroen Aerts and Otto de Keizer for their participation in the project and discussion on the methods, and Geert Jan van Oldenborgh for his comments on an earlier version of the manuscript.

Edited by: H. Cloke

\section{References}

Arnell, N. W. and Reynard, N. S.: The effects of climate change due to global warming on river flows in Great Britain, J. Hydrol., 183, 397-424, 1996.

Beersma, J. J.: Rainfall generator for the Rhine basin: description of 1000-year simulations, Publication 186-V, Royal Netherlands Meteorological Institute (KNMI), De Bilt, 18 pp., 2002.

Beersma, J. J. and Buishand, T. A.: Multi-site simulation of daily precipitation and temperature conditional on the atmospheric circulation, Clim. Res., 25, 121-133, 2003.

Beguería, S.: Uncertainties in partial duration series modelling of extremes related to the choice of the threshold value, J. Hydrol., 303, 215-230, 2005.

Belz, J., Brahmer, G., Buiteveld, H., Engel, H., Grabher, R., Hodel, H., Krahe, P., Lammersen, R., Larina, M., Mendel, H.-G., Meuser, A., Müller, G., Plonka, B., Pfister, L., and Van Vuuren, W.: Das Abflussregime des Rheins und seiner Nebenflüsse im 20. Jahrhundert: Analyse, Veränderungen, Trends, Report no. I22, International Commission for the Hydrology of the Rhine basin (CHR), Lelystad, The Netherlands, 377 pp., 2007.
Beniston, M., Stephenson, D., Christensen, O., Ferro, C., Frei, C., Goyette, S., Halsnaes, K., Holt, T., Jylhä, K., and Koffi, B.: Future extreme events in European climate: an exploration of regional climate model projections, Climatic Change, 81, 71-95, 2007.

Bergström, S. and Forsman, A.: Development of a conceptual deterministic rainfall runoff model, Nord. Hydrol., 4, 147-170, 1973.

Bernstein, L., Bosch, P., Canziani, O., Chen, Z., Christ, R., Davidson, O., Hare, W., Huq, S., Karoly, D., Kattsov, V., Kundzewicz, Z., Liu, J., Lohman, U., Mannin, M., Matsuno, T., Mene, B., Metz, B., Mirza, M., Nicholls, N., Nurse, L., Pachauri, R., Palutikof, J., Parry, M., Qin, D., Ravindranath, N., Reisinger, A., Ren, J., Riahi, K., Rosenzweig, C., Rusticucci, M., Schneider, S., Sokona, Y., Solomon, S., Stott, P., Stouffer, R., Sugiyama, T., Swart, R., Tirpak, D., Vogel, C., and Yohe, G.: Climate change 2007: Synthesis Report, Intergovernmental Panel on Climate Change (IPCC), Geneva, Fourth Assessment report, 1-52, 2007.

Buishand, T. A.: Statistics of extremes in climatology, Statistica Neerlandica, 43, 1-30, 1989.

Buishand, T. A. and Brandsma, T.: Multisite simulation of daily precipitation and temperature in the Rhine basin by nearestneighbor resampling, Water Resour. Res., 37, 2761-2776, doi:10.1029/2001wr000291, 2001.

Buonomo, E., Jones, R., Huntingford, C., and Hannaford, J.: On the robustness of changes in extreme precipitation over Europe from two high resolution climate change simulations, Q. J. Roy. Meteorol. Soc., 133, 65-81, doi:10.1002/qj.13, 2007.

Coles, S.: An introduction to statistical modeling of extreme values, Springer Verlag, London, UK, 2001.

Delworth, T. L., Broccoli, A. J., Rosati, A., Stouffer, R. J., Balaji, V., Beesley, J. A., Cooke, W. F., Dixon, K. W., Dunne, J., and Dunne, K.: GFDL's CM2 global coupled climate models, Part I: Formulation and simulation characteristics, J. Climate, 19, 643674, 2006.

De Wit, M. and Buishand, A.: Generator of Rainfall And Discharge Extremes (GRADE) for the Rhine and Meuse basins, Rijkswaterstaat RIZA Report no. 2007.027/KNMI publication 218, Lelystad/De Bilt, 76 pp., 2007.

Diaz-Nieto, J. and Wilby, R. L.: A comparison of statistical downscaling and climate change factor methods: Impacts on low flows in the River Thames, United Kingdom, Climatic Change, 69, 245-268, 2005.

Disse, M. and Engel, H.: Flood events in the Rhine basin: genesis, influences and mitigation, Nat. Hazards, 23, 271-290, doi:10.1023/a:1011142402374, 2001.

Flato, G.: The third generation coupled global climate model (CGCM3), Canadian Centre for Climate Modelling and Analysis, Canada, http://www.ec.gc.ca/ccmac-cccma/default. asp?lang=En $\backslash \& n=1299529 F-1$ (last access: 29 November 2012), 2005.

Fowler, H. J. and Ekström, M.: Multi-model ensemble estimates of climate change impacts on UK seasonal precipitation extremes, Int. J. Climatol., 29, 385-416, doi:10.1002/joc.1827, 2009.

Fowler, H. J., Blenkinsop, S., and Tebaldi, C.: Linking climate change modelling to impacts studies: recent advances in downscaling techniques for hydrological modelling, Int. J. Climatol., 27, 1547-1578, 2007. 
Frei, C., Schöll, R., Fukutome, S., Schmidli, J., and Vidale, P. L.: Future change of precipitation extremes in Europe: Intercomparison of scenarios from regional climate models, J. Geophys. Res., 111, D06105, doi:10.1029/2005jd005965, 2006.

Görgen, K., Beersma, J., Brahmer, G., Buiteveld, H., Carambia, M., De Keizer, O., Krahe, P., Nilson, E., Lammersen, R., Perrin, C., and Volken, D.: Assessment of Climate Change Impacts on Discharge in the Rhine River Basin: Results of the RheinBlick2050 Project, Report no. I-23, International Commission for the Hydrology of the Rhine basin (CHR), Lelystad, 229 pp., 2010.

Gordon, C., Cooper, C., Senior, C. A., Banks, H., Gregory, J. M., Johns, T. C., Mitchell, J. F. B., and Wood, R. A.: The simulation of SST, sea ice extents and ocean heat transports in a version of the Hadley Centre coupled model without flux adjustments, Clim. Dynam., 16, 147-168, doi:10.1007/s003820050010, 2000.

Gordon, H., Rotstayn, L., McGregor, J., Dix, M., Kowalczyk, E., O'Farrell, S., Waterman, L., Hirst, A., Wilson, S., and Collier, M.: The CSIRO Mk3 climate system model, Technical Paper No. 60, CSIRO Atmospheric Research, Aspendale, Australia, 134 pp., 2002.

Graham, L., Hagemann, S., Jaun, S., and Beniston, M.: On interpreting hydrological change from regional climate models, Climatic Change, 81, 97-122, 2007.

Hanel, M. and Buishand, T.: Analysis of precipitation extremes in an ensemble of transient regional climate model simulations for the Rhine basin, Clim. Dynam., 36, 1135-1153, doi:10.1007/s00382-010-0822-2, 2011.

Hasumi, H. and Emori, S.: K-1 coupled model (MIROC) description, Center for Climate System Research, K-1 Technical Report, University of Tokyo, Tokyo, 34 pp., 2004.

Jacob, D.: A note to the simulation of the annual and inter-annual variability of the water budget over the Baltic Sea drainage basin, Meteorol. Atmos. Phys., 77, 61-73, 2001.

Jones, R.: Generating high resolution climate change scenarios using PRECIS, Met Office, Hadley Centre, Exeter, UK, 35 pp., 2004.

Kendon, E. J., Jones, R. G., Kjellström, E., and Murphy, J. M.: Using and designing GCM-RCM ensemble regional climate projections, J. Climate, 23, 6485-6503, doi:10.1175/2010JCLI3502.1, 2010.

Klemeš, V.: Tall tales about tails of hydrological distributions I, J. Hydrol. Eng., 5, 227-231, doi:10.1061/(ASCE)10840699(2000)5:3(227), 2000a.

Klemeš, V.: Tall tales about tails of hydrological distributions II, J. Hydrol. Eng., 5, 232-239, doi:10.1061/(ASCE)10840699(2000)5:3(232), 2000b.

Kyselý, J. and Beranová, R.: Climate-change effects on extreme precipitation in central Europe: uncertainties of scenarios based on regional climate models, Theor. Appl. Climatol., 95, 361-374, doi:10.1007/s00704-008-0014-8, 2009.

Kyselý, J., Gaál, L., Beranová, R., and Plavcová, E.: Climate change scenarios of precipitation extremes in Central Europe from ENSEMBLES regional climate models, Theor. Appl. Climatol., 104, 529-542, doi:10.1007/s00704-010-0362-z, 2011.

Leander, R. and Buishand, T. A.: Resampling of regional climate model output for the simulation of extreme river flows, J. Hydrol., 332, 487-496, 2007.
Leander, R., Buishand, T., Van den Hurk, B., and De Wit, M.: Estimated changes in flood quantiles of the river Meuse from resampling of regional climate model output, J. Hydrol., 351, 331-343, 2008.

Lenderink, G., Van den Hurk, B., Van Meijgaard, E., Van Ulden, A., and Cuijpers, H.: Simulation of present-day climate in RACMO2: first results and model developments, Technical report no. TR-252, Royal Netherlands Meteorological Institute (KNMI), De Bilt, 24 pp., 2003.

Lenderink, G., Buishand, A., and Van Deursen, W.: Estimates of future discharges of the river Rhine using two scenario methodologies: direct versus delta approach, Hydrol. Earth Syst. Sci., 11, 1145-1159, doi:10.5194/hess-11-1145-2007, 2007.

Marti, O., Braconnot, P., Bellier, J., Benshila, R., Bony, S., Brockmann, P., Cadule, P., Caubel, A., Denvil, S., Dufresne, J., Fairhead, L., Filiberti, M. A., Fichefet, T., Foujols, M. A., Friedlingstein, P., Grandpeix, J. Y., Hourdin, F., Krinner, G., Lévy, C., Madec, G., Musat, L., De Noblet, M., Polcher, J., and Talandier, C.: The New IPSL Climate System Model: IPSLCM4, Note du Pôle de modélisation no. 26, Inst. Pierre Simon Laplace des Sciences de l'Environnement Global, Paris, Case 101, 86 pp., 2006.

Meehl, G., Covey, C., Delworth, T. L., and Latif, M.: The WCRP CMIP3 multi-model dataset: A new era in climate change research, B. Am. Meteorol. Soc., 88, 1383-1394, 2007.

Menzel, L., Thieken, A., Schwandt, D., and Bürger, G.: Impact of climate change on the regional hydrology-scenario-based modelling studies in the German Rhine catchment, Nat. Hazards, 38, 45-61, 2006.

Min, S., Legutke, S., Hense, A., and Kwon, W.: Internal variability in a 1000-year control simulation with the coupled climate model ECHO-G-I. Near-surface temperature, precipitation and mean sea level pressure, Tellus, 57, 605-621, 2005.

Nikulin, G., Kjellström, E., Hansson, U. L. F., Strandberg, G., and Ullerstig, A.: Evaluation and future projections of temperature, precipitation and wind extremes over Europe in an ensemble of regional climate simulations, Tellus A, 63, 41-55, doi:10.1111/j.1600-0870.2010.00466.x, 2011.

Photiadou, C. S., Weerts, A. H., and Van den Hurk, B. J. J. M.: Evaluation of two precipitation data sets for the Rhine River using streamflow simulations, Hydrol. Earth Syst. Sci., 15, 33553366, doi:10.5194/hess-15-3355-2011, 2011.

Prudhomme, C. and Davies, H.: Assessing uncertainties in climate change impact analyses on the river flow regimes in the UK Part 2: future climate, Climatic Change, 93, 197-222, 2009.

Prudhomme, C., Reynard, N., and Crooks, S.: Downscaling of global climate models for flood frequency analysis: where are we now?, Hydrol. Process., 16, 1137-1150, doi:10.1002/hyp.1054, 2002.

Rajagopalan, B. and Lall, U.: A $k$-nearest-neighbor simulator for daily precipitation and other weather variables, Water Resour. Res., 35, 3089-3101, 1999.

Roeckner, E., Bäuml, G., Bonaventura, L., Brokopf, R., Esch, M., Giorgetta, M., Hagemann, S., Kirchner, I., Kornblueh, L., Manzini, E., Rhodin, A., Schlese, U., Schulzweida, U., and Tompkins, A.: The atmospheric general circulation model ECHAM5, Part I: Model description, Report No. 349, Max Planck Institute for Meteorology Hamburg, 127 pp., 2003. 
Rowell, D. P.: A demonstration of the uncertainty in projections of UK climate change resulting from regional model formulation, Climatic Change, 79, 243-257, 2006.

Salas-Mélia, D., Chauvin, F., Déqué, M., Douville, H., Gueremy, J., Marquet, P., Planton, S., Royer, J., and Tyteca, S.: Description and validation of the CNRM-CM3 global coupled model, Centre National de Recherches Météorologiques (CNRM), Météo France, Toulouse, 2005.

Shabalova, M., Van Deursen, W., and Buishand, T.: Assessing future discharge of the river Rhine using regional climate model integrations and a hydrological model, Clim. Res., 23, 233-246, 2003.

Steppeler, J., Doms, G., Schättler, U., Bitzer, H., Gassmann, A., Damrath, U., and Gregoric, G.: Meso-gamma scale forecasts using the nonhydrostatic model LM, Meteorol. Atmos. Phys., 82, 75-96, 2003.

Te Linde, A. H., Aerts, J. C. J. H., Bakker, A. M. R., and Kwadijk, J. C. J.: Simulating low-probability peak discharges for the Rhine basin using resampled climate modeling data, Water Resour. Res., 46, W03512, doi:10.1029/2009wr007707, 2010.

Ulbrich, U. and Fink, A.: The January 1995 flood in Germany: Meteorological versus hydrological causes, Phys. Chem. Earth, 20, 439-444, 1995.

Van der Linden, P. and Mitchell, J.: ENSEMBLES; Climate change and its impacts: Summary of research and results from the ENSEMBLES project, Met Office Hadley Centre, Exeter, UK, 160 pp., 2009.
Van Montfort, M. and Witter, J.: The generalized Pareto distribution applied to rainfall depths, Hydrolog. Sci. J., 31, 151-162, 1986.

Wang, Q.: The POT model described by the generalized Pareto distribution with Poisson arrival rate, J. Hydrol., 129, 263-280, 1991.

Ward, P. J., Van Pelt, S. C., De Keizer, O., Aerts, J. C. J. H., and Beersma, J. J.: Probabilistic flood risk assessment, J. Flood Risk Manage., in review, 2012.

Weissman, I.: Estimation of parameters and larger quantiles based on the $k$ largest observations, J. Am. Stat. Assoc., 73, 812-815, 1978.

Wilby, R. L. and Harris, I.: A framework for assessing uncertainties in climate change impacts: Low-flow scenarios for the River Thames, UK, Water Resour. Res., 42, W02419, doi:10.1029/2005WR004065, 2006.

Wójcik, R., Beersma, J. J., and Buishand, T.: Rainfall generator for the Rhine basin, Multi-site generation of weather variables for the entire drainage area, Publication 186-V, Royal Netherlands Meteorological Institute (KNMI), De Bilt, 38 pp., 2000.

Yukimoto, S., Noda, A., Kitoh, A., Hosaka, M., Yoshimura, H., Uchiyama, T., Shibata, K., Arakawa, O., and Kusunoki, S.: Present-day climate and climate sensitivity in the Meteorological Research Institute coupled GCM version 2.3 (MRI-CGCM2.3), J. Meteorol. Soc. Jpn., 84, 333-363, 2006. 